\title{
Difusão da informação na administração pública
}

\author{
Dissemination of information within the public sector
}

\author{
Clarice Pereira de Paiva RIBEIRO' \\ Alana Deusilan Sester PEREIRA ${ }^{1}$ \\ Edson Arlindo da SILVA² \\ Walmer FARONI ${ }^{3}$
}

\section{Resumo}

A revolução da informação e da gestão do conhecimento na atualidade vem trazendo transformações significativas jamais vistas em tempos anteriores. As recentes revoltas populares que estão derrubando governos ditatoriais mostram a força das tecnologias de informação para mobilizar e aglutinar milhares de pessoas em torno de objetivos comuns. Nesse contexto, este estudo buscou compreender as constantes mudanças no ambiente e no arcabouço legal do país, através do seguinte questionamento: como os municípios brasileiros disseminam a informação para o cidadão sob a ótica das práticas da Gestão do Conhecimento e do Governo Eletrônico? Para isso, realizou-se uma pesquisa descritiva quantitativa, cuja avaliação consiste em 9 dimensões e 15 critérios, totalizando 187 pontos de verificação. Verificou-se que 62,96\% dos municípios estão evoluindo quanto à adoção de práticas relacionadas à disponibilização de informações sobre sua gestão fiscal. Também foi constatado que todos os municípios ainda necessitam de ferramentas avançadas que possam facilitar o acesso do contribuinte aos atos e serviços públicos. Com relação ao desenvolvimento da gestão e difusão da informação, em 77,78\% dos portais pesquisados, o acesso à informação não se dá de forma fácil, compreensível e rápida, contribuindo para o aumento da assimetria informacional entre governo e cidadão.

Palavras-chave: Administração pública. Gestão do conhecimento. Tecnologia da informação.

\begin{abstract}
The information and knowledge management revolution today is bringing significant changes never before seen. The recent uprisings that have been bringing down dictatorial governments show the power of information technology to mobilize and bring together thousands of people with common goals. Therefore, this study sought to understand the ever-changing environment and legal framework prevailing in this country, by posing the following question: How do municipalities disseminate information to citizens from a perspective of the practices of Knowledge Management and Electronic Government? To this end, we carried out quantitative, descriptive research, whose evaluation consisted of 9 dimensions and 15 criteria, a total of 187 check points. It was found that $62.96 \%$ of the cities are making progress in terms of the adoption of practices related to the disclosure of information concerning fiscal management. It was also found that all municipalities are still in need of more advanced tools that can facilitate taxpayer access to the acts and public services. With regard to the management and dissemination of information, in $77.78 \%$ of the portals surveyed, access to information is not easy or readily understandable, contributing to the increase in information asymmetry between Government and Citizen.
\end{abstract}

Keywords: Public administration. Knowledge management. Information technology.

\footnotetext{
1 Mestrandas, Universidade Federal de Viçosa, Programa de Pós-Graduação em Administração. Av. Peter Henry Rolf, s/n., Campus Universitário, Centro, Viçosa, MG, Brasil. Correspondência para/Correspondence to: C.P.P. RIBEIRO. E-mail: <clarice@camaravicosa.mg.gov.br>

2 Professor Doutor, Universidade Federal de Viçosa, Departamento de Administração. Viçosa, MG, Brasil.

3 Professor Doutor, Universidade Federal de Viçosa, Centro de Ciências Humanas. Viçosa, MG, Brasil.

Recebido em 26/2/2011, reapresentado em 11/6/2011 e aceito para publicação em 18/7/2011.
} 


\section{Introdução}

A década de 1990, no Brasil, foi marcada por transformações na estrutura política, social e econômica, essenciais para uma reestruturação governamental e administrativa, contribuindo para o redirecionamento da gestão pública no País. Tais transformações ocasionaram mudanças na forma de gestão, racionalização e modernização da estrutura administrativa, demandando um aumento no padrão de eficiência do Estado. Assim, foram estabelecidas práticas de gestão inovadoras, que propiciassem resultados mais efetivos para a sociedade (Dropa, 2003).

A modernização administrativa, transformando a cultura burocrática que permeava a administração pública brasileira, veio incutir uma nova cultura - denominada gerencial - com a implantação de processos e ferramentas que estimularam a mudança de comportamentos, estruturas e forma de gestão, em face das exigências de adequação às expectativas e necessidades atuais. Para isso, houve avanços notáveis na área de Tecnologia da Informação (TI) no setor público, propiciando ao cidadão acesso direto a um leque de serviços. Salles (2009) afirma que essa iniciativa é percebida em todas as esferas públicas, abrangendo até as prefeituras, com projetos de gestão e modernização administrativa efetivamente implantados e consolidados.

Para Matos (1988), a modernização administrativa é uma alternativa limitada para modificar a organização no campo estrutural, alterando normas, procedimentos e simplificando rotinas.

Segundo Marini (2003) a gestão do conhecimento recebe significativa atenção na nova gestão pública, como elemento decisivo da reforma gerencial. Esta deve estar voltada não somente para o ajuste fiscal, mas também para o resgate do déficit de desempenho da máquina pública e para a prestação de serviços à sociedade.
Dentre tantas definições encontradas na literatura sobre gestão do conhecimento, a mais adequada ao contexto da gestão pública é a do Comitê Executivo do Governo Eletrônico ${ }^{4}$, que a compreende como um conjunto de processos sistematizados, articulados e intencionais, capazes de incrementar a habilidade dos gestores públicos em criar, coletar, organizar, transferir e compartilhar informações e conhecimentos estratégicos que podem servir para a tomada de decisões, a gestão de políticas públicas e a inclusão do cidadão como produtor de conhecimento coletivo (Batista, 2006).

As instituições governamentais produzem muitas informações de interesse público, mas nem sempre as organizam, disponibilizam e disseminam adequadamente de modo a facilitar a criação do conhecimento. Não se tem uma gestão do conhecimento se não houver gestão da informação, pois muitas vezes aquela é utilizada de forma errada, saturando-se de informações e materiais inapropriados para a tomada de decisões.

De acordo com Reis (1993), para que a gestão da informação seja eficaz, é necessário que se estabeleça um conjunto de políticas coerentes que possibilitem o fornecimento de informação relevante, com qualidade suficiente, precisa, transmitida para o local certo, no tempo correto, com um custo apropriado e facilidade de acesso aos usuários autorizados.

Nesse sentido, percebeu-se que a gestão do conhecimento está baseada, em parte, na gestão da informação. Segundo Alvarenga Neto (2005) a gestão da informação é um dos componentes da gestão do conhecimento, pois esta inclui e incorpora outros aspectos, temas, abordagens e preocupações, como as questões de criação, uso e compartilhamento de informações e conhecimentos. Nessa perspectiva, a informação é um importante ativo para as organizações, principalmente no setor público.

O governo brasileiro implementou um conjunto de diretrizes do governo eletrônico (e-governo), com a

\footnotetext{
4 O Comitê Executivo do Governo Eletrônico (CEGE) foi criado por meio de decreto, em 18 de outubro de 2000. É responsável pela gestão do governo eletrônico brasileiro, presidido pelo Chefe da Casa Civil da Presidência da República. O Comitê tem como integrantes: Secretários-Executivos dos Ministérios; Secretário-Geral do Ministério das Relações Exteriores; Subchefe do Gabinete de Segurança Institucional da Presidência da República; Secretário de Organização Institucional do Ministério da Defesa; Subsecretário-Geral da Secretaria-Geral da Presidência da República; Secretário de Avaliação, Promoção e Normas da Secretaria de Comunicação de Governo da Presidência da República; Procurador-Geral da União; Subcorregedor-Geral da União; Diretor-Presidente do Instituto Nacional de Tecnologia da Informação. Entre as principais competências do Comitê Executivo de Governo Eletrônico, podem-se citar as seguintes: coordenar e articular a implantação de programas e projetos para a racionalização da aquisição e utilização da infraestrutura, dos serviços e das aplicações de tecnologia da informação e comunicação no âmbito da Administração Pública Federal; estabelecer diretrizes e estratégias para o planejamento da oferta de serviços e de informações por meio eletrônico, pelos órgãos e pelas entidades da Administração Pública Federal, dentre outros (Fresneda; Gonçalves, 2007).
} 
intenção de utilizar as novas tecnologias da informação, em especial a Internet, na prestação de serviços e disponibilização de informações junto aos cidadãos (Paula; Ciancone, 2007).

O governo eletrônico expressa uma estratégia pela qual o aparelho do Estado faz uso das novas tecnologias para oferecer à sociedade melhores condições de acesso à informação e aos serviços governamentais, ampliando a qualidade destes últimos e garantindo maior oportunidade de participação social no processo democrático (Jardim, 2000). Nesse diapasão, o autor afirma, ainda, que o governo eletrônico pode ampliar sua efetividade em quatro aspectos: 1) maior facilidade da sociedade em ter suas perspectivas consideradas pelos governos na (re)definição das políticas públicas; 2) obtenção, por parte da sociedade, de melhores serviços das organizações governamentais; 3) disponibilidade de serviços mais integrados, já que as diferentes organizações serão capazes de se comunicar mais efetivamente entre si; e 4) melhores níveis de informação para a sociedade, que poderá obter informação atualizada e compreensível sobre o governo, leis, regulamentos, políticas e serviços.

Segundo Lenk e Traunmüllerv (2001), o governo eletrônico pode ser analisado sob quatro perspectivas: 1) dos processos - visando repensar o modus operandi dos processos produtivos ora existentes no governo, em suas várias esferas, como, por exemplo, os processos de licitação para compras (e-procurement); 2) da cooperação - visando integrar os vários órgãos governamentais entre si e com as organizações privadas e não governamentais, de modo que o processo decisório possa ser agilizado, sem perda de qualidade, assim evitando fragmentação, redundância etc., hoje existentes nas relações entre esses vários atores; 3) da gestão do conhecimento - visando permitir ao governo, em suas diferentes esferas, criar, gerenciar e disponibilizar em repositórios adequados o conhecimento gerado ou acumulado por seus vários órgãos; e, 4) do cidadão - visando oferecer serviços de utilidade pública ao contribuinte.

Dentre as práticas de gestão do conhecimento existentes, Batista (2006) propôs uma tipologia mais simples, classificando-as em três categorias: 1) práticas relacionadas principalmente aos aspectos de gestão de recursos humanos, que facilitam a transferência, disseminação e compartilhamento de informações e conhe- cimento; 2) práticas ligadas primariamente à estruturação dos processos organizacionais, que funcionam como facilitadoras de geração, retenção, organização e disseminação do conhecimento organizacional; e 3) práticas cujo foco central é a base tecnológica e funcional que serve de suporte à gestão do conhecimento organizacional, incluindo automação da gestão da informação, aplicativos e ferramentas de TI para captura, difusão e colaboração.

Com base nessa tipologia, ferramentas de colaboração - como portais, sítios ou outros sistemas informatizados que capturam e difundem conhecimento e experiências - fazem parte das práticas com foco na base tecnológica e funcional. A adoção de meios eletrônicos para a prestação dos serviços governamentais exige que sítios e portais desenvolvidos e mantidos pela Administração Pública sejam fáceis de utilizar, relevantes e efetivos. Somente por meio da eficiência é possível aumentar a satisfação dos usuários de serviços eletrônicos e conquistar gradativamente uma parcela cada vez maior da população.

É, portanto, responsabilidade da Administração Pública Municipal oferecer ao cidadão a melhor experiência possível de acesso ao governo eletrônico, respeitando as particularidades da população atingida. A adoção de padrões traz muitas vantagens na gestão de sítios, como a garantia do nível de qualidade, pois possibilita a mensuração de resultados. Fornece também requisitos para a correta contratação da equipe ou empresa que desenvolve e/ou mantém o sítio. Além disso, a padronização dos ambientes acelera o processo de adaptação e migração para tecnologias mais modernas. Nesse sentido, alguns trabalhos foram elaborados com foco na avaliação de portais, dentre os quais os estudos de Vaz (2003), Villela (2003), Simão e Rodrigues (2005), Biz (2009) e Pereira etal. (2010).

A partir dessas exposições, e buscando avaliar como se dá a disponibilização da informação aos munícipios por meio da Internet, chega-se ao seguinte questionamento: como os municípios brasileiros disseminam a informação para o cidadão, considerando os preceitos da Gestão do Conhecimento e do Governo Eletrônico?

Assim, o objetivo primordial deste trabalho foi investigar o nível de desenvolvimento da prática de gestão do conhecimento - o portal - nos municípios, conside- 
rando o período de 2000 a 2010. Foram utilizadas como fonte de dados para este estudo as informações que os municípios disponibilizaram na Internet. Devido à sua complexidade, esta investigação científica considerou inicialmente apenas as capitais brasileiras e o Distrito Federal. Mais especificamente, almejou-se: 1) definir os critérios para análise da difusão da informação dos municípios; 2) elaborar questionários para avaliar a quantidade e qualidade das informações na Internet (site) disponibilizadas pelos municípios; 3) avaliar os sítios dos municípios, de acordo com os preceitos das políticas de governo eletrônico; e 4) traçar um perfil dos municípios, de acordo com os dados apurados na pesquisa.

\section{Gestão do conhecimento}

A Gestão do Conhecimento pode ser vista como uma coleção de processos que governa a criação, disseminação e utilização do conhecimento para atingir plenamente os objetivos da organização (Davenport; Prusak, 1998). Ela se beneficia, e muito, das novas tecnologias de informação e de comunicação.

Drucker (1997) afirma que o conhecimento é a informação eficaz em ação, focalizada em resultados, sendo a ferramenta apta a tornar produtivo o conhecimento. Já Nonaka (1994) expõe que a informação é um fluxo de mensagens ou propósitos que adiciona força para reestruturar ou mudar o conhecimento. Assim, o conhecimento é a informação que foi interpretada, categorizada, aplicada e revisada, enquanto a análise da informação produz o conhecimento, que pode ser aplicado na solução de problemas e na tomada de decisões.

Com isso, para que haja a gestão do conhecimento é necessário que a informação seja disponibilizada de maneira eficiente sendo importante a realização da gestão da informação.

Além das pessoas, diferentes recursos de informação são mobilizados para que a gestão da informação cumpra sua função. Esses recursos compreendem tecnologia da informação, fontes, serviços e sistemas, que atendam não só aos processos de organização da informação, mas também às necessidades de informação, colocando-se o foco nos fluxos e ações referentes à informação, e não somente nos sistemas de informação (Silva; Tomael, 2007).
A Gestão da Informação é entendida como a gestão eficaz de todos os recursos de informação relevantes para a organização, sejam eles recursos gerados internamente ou externamente, com o apoio da tecnologia de informação. O objetivo de gerenciar a informação é melhorar o acesso e distribuição da informação, fazendo com que a coleta, tratamento e disseminação da mesma possam ser automatizados (Costa et al., 2010).

Fresneda e Gonçalves (2007) definem gestão do conhecimento como facilitador dos processos pelos quais o conhecimento é criado, compartilhado e utilizado para maximizar a efetividade da organização, sendo que a partir das 'práticas de gestão do conhecimento' é possível identificar como as organizações gerenciam o conhecimento.

Dentre os vários conceitos presentes na literatura sobre gestão do conhecimento, a que mais se aplica ao setor público pode ser entendida como a prática de agregar valor à informação e de distribuí-la. Assim, equivale a um conjunto de processos que visa colaborar para a criação, captura e compartilhamento do conhecimento tácito e implícito entre as pessoas de uma organização, tendo como objetivo a criação de ferramentas que auxiliem na disseminação desses conhecimentos dentro dela, tais como portais e sítios.

A gestão do conhecimento é como uma mistura
fluida da experiência condensada, valores, infor-
mação contextual e insight experimentado, a
qual proporciona uma estrutura para a avaliação
e incorporação de novas experiências e infor-
mações. Ele tem origem e é aplicado na mente
dos conhecedores. Nas organizações, ele costuma
estar embutido não só em documentos de repo-
sitórios, mas também em rotinas, processos,
práticas e normas organizacionais (Davenport;
Prusak, 1998, p.6).

Assim, Coelho (2004) acrescenta que a gestão do conhecimento é o processo que tenta assegurar que as atividades de uma organização pública sejam transformadas em novos conhecimentos, ou seja, em novos processos e em produtos ou soluções inovadoras. A gestão do conhecimento é um novo modelo de gerenciamento, focado na aprendizagem contínua, na estratégia da inovação e na geração de conhecimentos.

A importância da gestão do conhecimento, como fator de sucesso das organizações, já é evidenciada desde 
o início dos anos 1990, quando Drucker (1993) assinala que o recurso realmente controlador, o fator de produção absolutamente decisivo, não é o capital, a terra ou a mão de obra, e sim o conhecimento. O autor também afirma que o valor é criado pela produtividade e pela inovação, que são aplicações do conhecimento ao trabalho. 0 conhecimento passa a ser um ativo valioso; portanto, motivar, recompensar e reter as pessoas que têm conhecimento é um foco para que as instituições sejam bem sucedidas.

Teixeira Filho (2000) apresenta os seguintes objetivos da gestão do conhecimento: formular uma estratégia organizacional para aquisição, organização e aplicação do conhecimento; implantar estratégias orientadas ao conhecimento; promover a melhoria contínua dos processos do negócio, enfatizando a geração e utilização do conhecimento; monitorar e avaliar os resultados obtidos mediante a aplicação do conhecimento; reduzir os custos associados à repetição de erros; e melhorar os serviços prestados.

Há um baixo nível de conscientização entre os administradores públicos sobre a importância da gestão do conhecimento e, consequentemente, presencia-se a falta de priorização e alocação de recursos em projetos de tal natureza. Também, sabe-se que a Administração Pública opera com orçamentos bem reduzidos e necessidades amplas.

Além de aumentar a efetividade da ação pública no tratamento de temas relevantes para a sociedade de maneira competente, com o mínimo de recursos e o máximo de tempestividade, as organizações públicas devem gerir o conhecimento para: (i) tratar de maneira adequada e com rapidez desafios inesperados e desastres; (ii) preparar cidadãos, organizações não governamentais e outros atores sociais para atuar como parceiros do Estado na elaboração e implementação de políticas públicas; (iii) promover a inserção social, a redução das desigualdades sociais e um nível aceitável de qualidade de vida para a população, por meio da construção, manutenção e ampliação do capital social e intelectual das empresas; e (iv) criar uma sociedade competitiva na economia regional e global, por meio da educação dos cidadãos, para que estes se tornem trabalhadores competentes do conhecimento, e por meio do desenvolvimento das organizações, para que estas se tornem competitivas em todas as áreas do conhecimento (Batista, 2006).
A gestão do conhecimento é compreendida, no âmbito das políticas de governo eletrônico, como um conjunto de processos sistematizados, articulados e intencionais, capazes de assegurar a habilidade de criar, coletar, organizar, transferir e compartilhar conhecimentos estratégicos, que podem servir para a tomada de decisões, para a gestão de políticas públicas e para inclusão do cidadão como produtor de conhecimento coletivo (Departamento de Governo Eletrônico (DGE), Brasil, 2007).

As práticas de gestão do conhecimento demonstram como as organizações gerenciam o conhecimento. Serão consideradas práticas de gestão do conhecimento as atividades que reúnam as seguintes características (Batista et al., 2005) execução regular; finalidade de gestão da organização; base em padrões de trabalho; preocupação com a produção, retenção, disseminação, compartilhamento ou aplicação do conhecimento dentro das organizações e na relação destas com o mundo exterior.

Dentre as práticas existentes, destacam-se, no setor público, os portais. Segundo Vaz (2007), os portais podem ser vistos como um fenômeno multidimensional, que envolve tecnologia da informação, organização dos serviços públicos e da política de atendimento ao cidadão, além de reforçarem o relacionamento entre governo e cidadão. O autor aponta que há uma dimensão tecnológica, porque a implantação de um portal passa por uma decisão com esse viés e se sujeita aos mesmos requisitos de um portal de outra organização. Há também uma dimensão organizacional e de prestação de serviço, porque é um recurso para atendimento ao cidadão, além de uma dimensão política, já que marca uma interação entre governo e cidadão.

Terra e Gordon (2002) listam os seguintes problemas vivenciados pelo usuário que dificultam justificariam a utilização do portal: dificuldade em acessar informações; redundância e duplicidade de informação; dificuldade para indivíduos em publicar informação para o resto da organização ou para a sociedade; existência de vários métodos para se acessar a informação; necessidade de intermediação da área de tecnologia para acesso à informação; dificuldade de integração dos dados. Pode-se também estudar um portal municipal em sua dimensão organizacional e de prestação de serviços.

O portal pode ser visto como auxílio na prestação de serviços, ou seja, como um recurso que uma prefeitura 
municipal emprega para compor seu sistema de atendimento ao cidadão-usuário de serviços públicos. Ainda, pode ser visto como um meio de interação entre a administração municipal e os cidadãos, uma vez que a utilização do portal municipal reflete as próprias escolhas do governo municipal em termos de promoção de direitos dos cidadãos (Vaz, 2007).

\section{Governo eletrônico ou e-governo}

O governo eletrônico surgiu a partir da implantação do Programa Sociedade da Informação no Brasil, iniciada em 1999 e finalizada em 2000, com a publicação de um documento chamado "Livro Verde". Consistia no desenvolvimento de ações para a melhoria da prestação de serviços pela Internet, com menores custos e mais qualidade, além de maior transparência e estímulo ao controle social (Sociedade da Informação no Brasil, 2000). Apresentava como principais objetivos a melhoria do trabalho interno do governo, o aperfeiçoamento da relação com os fornecedores e o melhor atendimento ao cidadão (Parreiras et al., 2004).

O e-governo pode ser entendido como o uso, pelos governos, das novas tecnologias da informação na prestação de serviços e de informações aos cidadãos, fornecedores e servidores da própria Administração Pública, ou seja, é a atuação do poder público via rede mundial de computadores. Além de mais econômico e rápido que o atendimento face a face, o uso da Internet na função pública cria possibilidades extraordinárias de ampliar o controle da gestão fiscal por parte da população, facilitando o exercício daquilo que se convencionou accountability, isto é, a obrigatoriedade de prestar contas ao cidadão (Fernandes; Afonso, 2001).

Devido à existência de várias definições sobre governo eletrônico na literatura, foram adaptadas de Modro (2005, p.56) as mais relevantes para este estudo, a saber: - O e-governo é a transformação das relações
internas e externas do setor público, por meio
de operações baseadas na Internet e nas TIC, para
otimizar os serviços e processos governamentais
e a participação (Di Maio et al., 2002).
- O e-governo se refere ao uso da Internet e de
outros dispositivos digitais para que o setor público forneça serviços e informações (West, 2004).

- Para resumir, o e-governo não é somente a modernização da administração pública por meio das TIC, mas é a chave para permitir a construção de um governo cooperativo e centrado no cidadão, ou um governo moderno (Leitner, 2003).

- O e-governo pode ser definido como a transformação das relações internas e externas do setor público através das tecnologias de informação e comunicação para promover uma melhor prestação de contas, aumentar a eficiência e eficácia dos serviços públicos, e aumentar a participação da população (ADB Institute, 2004).

- O e-governo se refere a situações onde as agências administrativas, legislativas ou judiciais públicas digitalizam suas operações internas e externas e utilizam serviços de rede para melhorar a qualidade dos serviços públicos. O e-governo inclui: a) prover maior acesso a informações públicas; b) permitir que a população interaja com os órgãos públicos; e c) melhorar a prestação de contas públicas por meio da transparência das operações e processos governamentais (GBDE, 2004).

A intenção do Governo com a política de governo eletrônico foi estabelecer um novo paradigma de inclusão digital, focado no cidadão, com uma gestão pública de qualidade e transparente, permitindo a simplificação dos processos para atender às necessidades coletivas - um "governo ao alcance de todos" (Sociedade da Informação no Brasil, 2000).

Dessa forma, o Estado trabalha na promoção da cidadania, através da inclusão social e da ampliação do uso das tecnologias de informação pela sociedade civil, possibilitando a universalização e democratização do acesso às informações governamentais. Essa democratização pode ser alcançada através do governo eletrônico, utilizando como meio a Internet e objetivando a interação entre a Sociedade e o Estado.

O governo eletrônico representa uma profunda mudança na organização social e econômica, é um fenômeno com potencial transformador elevado, uma vez que a dinâmica das atividades sociais será inevitavelmente afetada pela infraestrutura das informações disponíveis. Representa uma oportunidade para prestar contribuições sociais e resgatar a dívida social, além 
de tentar alavancar seu desenvolvimento. Constitui um programa de concepção e integração de ações públicas cujo papel é articular ações tecnológicas voltadas para a sustentabilidade de um padrão de desenvolvimento que respeite e busque o equilíbrio de cada região (Souza, 2005, p.39).

O governo eletrônico permitirá à sociedade o acompanhamento das contas públicas de modo muito mais eficiente e dinâmico. Com as informações disponíveis na rede, o cidadão terá melhores condições de controlar a gestão dos recursos e a prestação dos serviços, cobrando da Administração as medidas que julgar necessárias ao controle da corrupção e do desperdício.

De acordo com Souza (2005, p.85)"a qualidade da informação é um dos aspectos mais importantes a serem considerados, devido ao volume exponencialmente crescente de informações veiculadas na Internet".

Nesse contexto, não é suficiente apenas a oferta de informações nos portais governamentais, mas também se deve avaliar a sua qualidade; a informação deve estar alinhada às necessidades da população.

\section{O município e o distrito}

Atualmente, o Estado Federativo Brasileiro, conforme estabelece o artigo 18 da Constituição Federal de 1988, compreende a União, os 26 Estados, o Distrito Federal e os 5564 Municípios, todos dotados de autonomia político-administrativa. Dessa forma, o sistema federativo consiste na partilha de atribuições e distribuição de competências entre entes federados, buscando atender às demandas orientadas do setor público, em cada nível de governo ou unidade federativa.

A especificidade do Distrito Federal como uma unidade da federação diferenciada das demais origina-se do fato de se tratar de uma região cuja urbanização foi planejada para receber a capital do país e que, em decorrência dessa decisão, acabou por se caracterizar pelo predomínio de atividades econômicas preferencialmente relacionadas à administração pública, sendo vedada sua divisão em municípios, conforme artigo 32 da CF/88 (Brasil, 2002).

O município, na administração pública brasileira, corresponde ao poder local e, com a Carta Magna de 1988, tornou-se uma unidade política autônoma e res- ponsável pela gestão dos serviços públicos dentro de suas fronteiras. Conforme preceituam Matias e Campello (2000, p.21), o Município representa:

[...] o espaço físico onde ocorre a produção de bens e serviços, a circulação de mercadorias, e onde realmente são implementadas todas as ações, sejam de origem da esfera Federal, Estadual ou Municipal, ou de origem privada. Portando, o poder local, se apresenta mais próximo dos problemas, bem como suscetível ao controle da sociedade, mostrando-se mais adequado para atender às demandas sociais.

Para que as unidades da federação possam exercer os fins para os quais foram criadas, necessitam de uma estrutura que possibilite o seu funcionamento, que é denominada de Administração Pública. Andrade (2007, p.13) define-a como "todo o aparelhamento preordenado à realização de serviços, visando à satisfação das necessidades coletivas".

À Administração Pública cabe a operacionalização das funções do Estado, cuja tarefa é promover um modelo de desenvolvimento sustentável, com ações políticas e públicas que supram as carências da sociedade com educação, saúde, segurança, transporte, cultura, habitação, meio ambiente, entre outros benefícios que promovam o bem-estar social. Neste estudo, será considerada a Administração Pública Municipal e do Distrito Federal.

\section{Métodos}

Este trabalho foi realizado a partir de uma pesquisa descritiva, cuja finalidade foi expor as características, relações ou propriedades existentes no grupo pesquisado. Gil (1996, p.104) relata que"na pesquisa descritiva os fatos são observados, registrados, analisados, classificados e interpretados, sem que o pesquisador interfira neles, permitindo a exposição de suas características, relações ou propriedades".

Inicialmente, procedeu-se à pesquisa bibliográfica, considerando-se também a legislação, com o propósito de definir os conceitos e critérios utilizados na avaliação da qualidade da informação disponibilizada nos websites.

O delineamento e o desenvolvimento deste trabalho deram-se sob a forma de um levantamento, com a finalidade de investigar as práticas de disseminação da informação e prestação de serviços nos portais das Pre- 
feituras das 26 capitais brasileiras e do Distrito Federal, totalizando 27 sites governamentais, referentes ao Poder Executivo de cada unidade da federação. Para se chegar aos websites utilizou-se como critério a pesquisa em sites de busca (por exemplo, <www.google.com.br>) da combinação "prefeitura/câmara do município X (UF)" ou similar. Esta seria a forma mais direta para um cidadão leigo em "tecnologias de informação" encontrar dados sobre o seu município.

A metodologia pode ser sintetizada da seguinte forma: os 187 Pontos de Verificação (PV) correspondem às questões analisadas em cada página eletrônica, recebendo cada uma a nota 0 (ausência) ou 1 (presença). Cada PV foi determinado de acordo com os 15 critérios de apreciação que fazem parte de 9 dimensões de avaliação dos websites governamentais, sob a ótica do Manual de Indicadores e Métricas para avaliação de e-Serviços do Governo Eletrônico (Brasil, 2007) e adaptado a partir do método utilizado por Ribeiro e Zuccolotto (2008).

A coleta foi realizada a partir de quatro questionários dicotômicos fechados, contendo 187 pontos de verificação. Os dados dos websites das Prefeituras Municipais, obtidos em outubro de 2010, foram analisados considerando 9 dimensões: maturidade (D1), comunicabilidade (D2), disponibilidade (D3), multiplicidade de acesso (D4), acessibilidade (D5), confiabilidade (D6), usabilidade (D7), transparência (D8), prestação de contas (D9), conforme demonstrado no Quadro 1:

A nota final de avaliação dos websites corresponde à soma dos resultados obtidos em "qualidade da informação" (dimensões D1 a D8, cada uma delas com peso 1) e "quantidade de informações" (dimensão D9, com peso 0,5), conforme mostra a equação:

$$
\mathrm{NF}=\mathrm{ND}_{1}+\mathrm{ND}_{2}+\mathrm{ND}_{3}+\ldots . .+\left[\left(\mathrm{ND}_{9}\right) / 2\right] \ldots . . . \text {, onde: }
$$

$\mathrm{NF}=$ Nota Final, correspondente à soma da pontuação nas dimensões;

$\mathrm{ND}_{\mathrm{x}}=$ Notas das dimensões, abrangendo a soma dos pontos de verificação (0 ou 1).

Dessa forma, a avaliação final da qualidade do portal quanto à difusão informacional é a soma do total de escores obtidos em cada ponto de verificação que indica a situação de cada município quanto ao desenvolvimento de políticas direcionadas para a difusão da informação. Cada portal pode obter de 0 (zero) a 100 (cem) pontos, sendo que a pontuação nula (zero) implica dizer ausência de todos os critérios analisados, e a obtenção de 100 (cem) pontos significa que o município atende a todos os critérios investigados na pesquisa e se preocupa em adotar como programa de governo práticas direcionadas à difusão da informação. As informações coletadas dos 27 municípios foram compiladas utilizando o software Statistical Package for the Social Sciences (SPSS), para que se fizessem as devidas análises estatísticas com a finalidade de alcançar o objetivo deste estudo.

\section{Resultados e Discussão}

\section{Análise das informações sobre a gestão fiscal nos websites}

Os dados apurados mostraram que a maioria dos municípios (55,56\%) apresentaram razoavelmente as informações sobre sua gestão fiscal (Figura 1). Destacam-se os municípios de Vitória (com escores de 77,60) e Curitiba $(77,20)$, que disponibilizaram em suas páginas eletrônicas uma boa quantidade de dados sobre suas contas, demonstrando com transparência como os recursos públicos estão sendo aplicados. Observou-se que a capital brasileira menos transparente foi Macapá (com índice de 1,20).

Para esse atributo, todas as capitais deveriam apresentar pontuação integral (100), já que a prestação de contas está determinada pelos dispositivos legais vigentes no País.

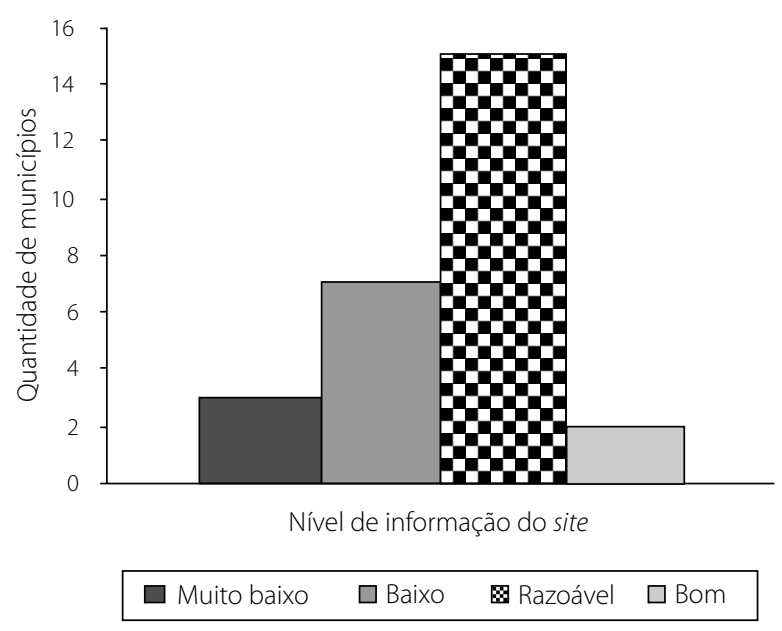

Figura 1. Nível de informação sobre a gestão fiscal dos municípios. Fonte: Dados de pesquisa, 2010. 
Quadro 1. Dimensão, critérios, pontos de verificação, notas e pesos das nove dimensões analisadas nos websites municipais.

\begin{tabular}{|c|c|c|c|c|}
\hline Dimensão & Critério & Pontos de verificação & Nota da dimensão & Peso \\
\hline 1 & Informação & $\begin{array}{l}\text { Horário de funcionamento, endereço, missão da instituição, entre } \\
\text { outros. }\end{array}$ & 4 & 1 \\
\hline 1 & Interação & $\begin{array}{l}\text { Formulários on-line, orientação sobre serviços, acesso a base de } \\
\text { dados, fóruns para discussão, chats, enquetes, acesso por celulares, } \\
\text { palms, etc. }\end{array}$ & 9 & 1 \\
\hline 1 & Transação & $\begin{array}{l}\text { Transações formais de pagamento de taxas e recebimento on-line de } \\
\text { reembolso. }\end{array}$ & 2 & 1 \\
\hline 2 & Contato e Ajuda & $\begin{array}{l}\text { Correio eletrônico, telefone, FAQ, ajuda on-line ou por telefone, entre } \\
\text { outros. }\end{array}$ & 7 & 1 \\
\hline 3 & Prontidão & Disponibilidade 24 horas por dia e 7 dias por semana. & 2 & 1 \\
\hline 4 & Tipos de acesso & SMS, quiosques, calls centers, Intermediação pessoal, etc. & 5 & 1 \\
\hline 5 & Acessibilidade & Selo de acessibilidade & 1 & 1 \\
\hline 6 & $\begin{array}{l}\text { Privacidade e atualização do } \\
\text { conteúdo }\end{array}$ & Política de privacidade e data de atualização das páginas & 2 & 1 \\
\hline 7 & Linguagem compreensível & $\begin{array}{l}\text { Apresenta correção gramatical e ortográfica, clareza de comunicação, } \\
\text { organização lógica, evita uso de jargões, gírias, entre outros, presença } \\
\text { de gráficos e notas explicativas para entendimento da informação. }\end{array}$ & 4 & 1 \\
\hline 7 & Navegabilidade & $\begin{array}{l}\text { Menus intuitivos, mapas do site, indicadores de novas informações } \\
\text { disponíveis, ferramentas de busca, "migalhas de pão", uniformidade } \\
\text { de design, URL de fácil digitação, presença de links "mortos/que- } \\
\text { brados", pesados para carregar, imagens para orientar o cidadão, } \\
\text { filtros de acesso por público-alvo, áreas de interesse ou outras alterna- } \\
\text { tivas, responsável para direcionamento das dúvidas, descrição dos } \\
\text { serviços do site e instrução para uso dos serviços. }\end{array}$ & 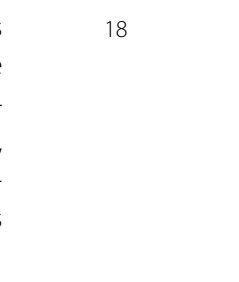 & 1 \\
\hline 7 & Pró-atividade & $\begin{array}{l}\text { Opção para emissão de segunda via de boletos, documentos, entre } \\
\text { outros e histórico dos serviços utilizados pelo cidadão. }\end{array}$ & 2 & 1 \\
\hline 8 & Responsabilidade & Indicação do responsável pelos atos administrativos. & 1 & 1 \\
\hline 8 & Acompanhamento & $\begin{array}{l}\text { Indicação da situação/status da solicitação de benefícios, reembolsos, } \\
\text { processos de inadimplência, etc., se há indicação de quando a página } \\
\text { está inacessível, incompleta ou em construção. }\end{array}$ & 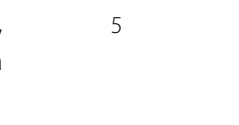 & 1 \\
\hline 8 & Divulgação & $\begin{array}{l}\text { Indicação do grau de satisfação com o serviço, relação dos serviços } \\
\text { mais utilizados, se existem indicadores sobre a economia e rapidez } \\
\text { com a utilização de serviços online. }\end{array}$ & 3 & 1 \\
\hline 9 & Accountability & $\begin{array}{l}\text { Há informações pormenorizadas sobre receitas, despesas, balanços } \\
\text { municipais, dados do controle externo, PPA, LDO, LOA e processos } \\
\text { de compra realizados no município nos anos de } 2001 \text { a } 2010 \text {. }\end{array}$ & 120 & 0,5 \\
\hline
\end{tabular}

Fonte: Dados da pesquisa, 2010.

\section{Análise da estrutura das páginas governamentais}

Grande parte dos sites do Poder Executivo municipal apresentam portais com atributos que permitem disponibilizar à população uma página eletrônica de fácil acesso e inteligível, pois obtiveram escores medianos na avaliação, conforme mostra a Figura 2. A Prefeitura de Belo Horizonte, com melhor desempenho entre as cidades analisadas, obteve 68,40\% do total de pontos verificados. Isso permite inferir que, apesar de ser uma página acessível ao usuário, ainda há deficiências a serem sanadas para a oferta de e-services de melhor qualidade à população. A capital com pior desempenho foi Macapá (17,40\% de aproveitamento) cujo website é pesado e de difícil interação com o usuário, principalmente se leigo em tecnologias da informação. 
As principais carências apuradas foram: falta de ferramentas que permitam realizar pesquisas de informações no site, não utilização de gráficos e notas explicativas para facilitar a compreensão do assunto, ausência de informação sobre a possibilidade de acessar novos serviços, presença de links mortos e/ou quebrados, de carregamento pesado, ausência da indicação dos responsáveis pelos atos administrativos, entre outros problemas. A instituição de ferramentas de fácil entendimento como gráficos, FAQ, fóruns e ajuda bibliográfica, pode auxiliar o contribuinte a localizar no site as informações, bem como a entendê-las e tomar posição a respeito da gestão empreendida pelo administrador público.

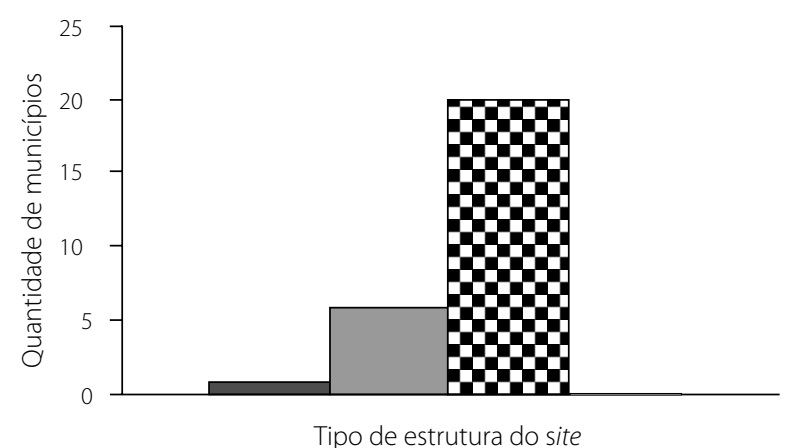

$\square$ Muito ruim $\square$ Ruim Razoável $\square$ Boa

Figura 2. Estrutura dos websites governamentais das capitais brasileiras.

Fonte: Dados da pesquisa, 2010.

\section{Avaliação geral das páginas eletrônicas}

A análise geral dos websites governamentais permite inferir que a Prefeitura Municipal da cidade de Belo Horizonte é a que mais se destacou, obtendo um escore de 88,79, quase 70,00\% de aproveitamento com relação aos atributos analisados neste trabalho (Tabela 1). Pode-se dizer que seu gestor teve a preocupação de investir em tecnologias de informação como mecanismos facilitadores da comunicação entre governo e cidadão. Também sobressaíram os sites das Prefeituras de Cuiabá e Vitória (escores de 85,76 e 84,96, respectivamente).

Macapá obteve o pior índice de aproveitamento (nota final de 12,38) demonstrando a precariedade da página com relação aos atributos mínimos para uma boa navegação, o que interfere negativamente na comunicação entre o governo e o contribuinte.

Quando se faz a análise agrupada dos municípios por região geográfica, verifica-se que, na média, a região Centro-Oeste (55,38\% de aproveitamento médio) foi a que demonstrou maior desenvolvimento com relação ao uso da TIC, com destaque para Cuiabá (Figura 3). Isso pode ser explicado pela grande quantidade de informações disponibilizadas para o cidadão sobre a gestão fiscal da Administração Pública, em consonância com a Lei de Responsabilidade Fiscal.

Apurou-se equilíbrio entre as regiões Sul, Nordeste e Sudeste quanto ao nível de difusão da informação. A

Tabela 1. Classificação dos municípios quanto ao nível de difusão da informação em seus websites oficiais.

\begin{tabular}{|c|c|c|c|c|c|c|c|c|c|}
\hline Ordem & Município & Dimensão 1 a 8 & Dimensão 9 & Nota Final & Ordem & Município & Dimensão 1 a 8 & Dimensão 9 & Nota Final \\
\hline 10 & Belo Horizonte & 45,83 & 42,96 & 88,79 & $15^{\circ}$ & João Pessoa & 34,88 & 31,26 & 66,14 \\
\hline $2^{\circ}$ & Cuiabá & 39,20 & 46,56 & 85,76 & $16^{\circ}$ & Teresina & 34,68 & 31,44 & 66,12 \\
\hline $3^{\circ}$ & Vitória & 38,64 & 46,32 & 84,96 & $17^{\circ}$ & Natal & 34,97 & 30,12 & 65,09 \\
\hline $4^{\circ}$ & São Paulo & 42,19 & 40,08 & 82,27 & $18^{\circ}$ & Belém & 35,64 & 28,98 & 64,62 \\
\hline $5^{\circ}$ & Curitiba & 37,61 & 44,22 & 81,83 & $19^{\circ}$ & Florianópolis & 31,42 & 30,90 & 62,32 \\
\hline $6^{\circ}$ & Salvador & 41,79 & 39,24 & 81,03 & $20^{\circ}$ & Palmas & 36,72 & 23,94 & 60,66 \\
\hline 70 & Fortaleza & 42,30 & 36,24 & 78,54 & $21^{\circ}$ & Rio Branco & 34,84 & 23,64 & 58,48 \\
\hline $8^{\circ}$ & Rio de Janeiro & 37,12 & 38,76 & 75,88 & $22^{\circ}$ & Boa Vista & 30,84 & 27,24 & 58,08 \\
\hline $9^{\circ}$ & Porto Alegre & 37,14 & 35,70 & 72,84 & $23^{\circ}$ & São Luís & 30,95 & 22,02 & 52,97 \\
\hline $10^{\circ}$ & Goiânia & 34,30 & 38,40 & 72,70 & $24^{\circ}$ & Brasília & 26,20 & 26,34 & 52,54 \\
\hline $11^{\circ}$ & Campo Grande & 40,20 & 30,12 & 70,32 & $25^{\circ}$ & Maceió & 34,53 & 9,84 & 44,37 \\
\hline $12^{\circ}$ & Recife & 33,01 & 35,46 & 68,47 & $26^{\circ}$ & Aracaju & 34,01 & 7,74 & 41,75 \\
\hline $13^{\circ}$ & Manaus & 38,64 & 28,26 & 66,90 & 270 & Macapá & 11,66 & 0,72 & 12,38 \\
\hline $14^{\circ}$ & Porto Velho & 31,53 & 35,04 & 66,57 & & & & & \\
\hline
\end{tabular}

Fonte: Dados da pesquisa, 2010. 


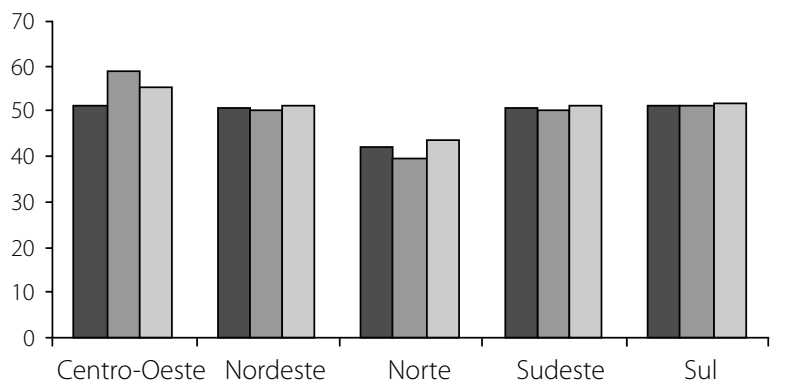

$\square$ Qualidade da informação (D1 a D8) $\square$ Quantidade de informação (D9) $\square$ Avaliação geral

Figura 3. Avaliação das características dos websites governamentais das regiões geográficas.

Fonte: Dados da pesquisa, 2010.

região Norte foi a que apresentou os piores escores médios com relação ao desenvolvimento de ações direcionadas para a utilização de TIC como mecanismo facilitador da comunicação entre contribuinte e Administração Pública. Esse fato pode ser creditado aos baixos índices de desenvolvimento econômico e social e também à ausência de profissionais qualificados na localidade, distante dos grandes centros de tecnologia.

\section{Conclusão}

A interação entre cidadão e governo pode implicar o atendimento efetivo das demandas coletivas, visto que o acesso à informação é condição essencial para o debate acerca dos problemas socioeconômicos de determinada região, visando à sua solução. Nesse contexto, os conceitos e práticas da Gestão do Conhecimento e do Governo Eletrônico são elementos básicos para garantir uma melhor Administração Pública e atingir a democracia digital.

O sucesso da política de Governo Eletrônico depende da definição e publicação de políticas, padrões, normas e métodos para sustentar as ações de implantação e operação do programa, de modo a superar uma série de fatores críticos que possam comprometer o êxito da iniciativa.

Nesse sentido, o presente estudo teve por objetivo investigar o nível de desenvolvimento de uma prática de gestão do conhecimento - o portal - nas capitais brasileiras e no Distrito Federal. Apurou-se que grande parte dos municípios $(77,78 \%)$ apresenta um nível de gestão da informação em seus portais de ruim a bom, o que permite concluir que ainda são necessárias ações mais pontuais e efetivas para que as tecnologias de informação possam atuar como ferramenta auxiliar dos governos municipais na promoção da participação social.

Quanto à divulgação de informações sobre a gestão fiscal dos municípios, percebeu-se que esta é uma prática que está evoluindo nas capitais brasileiras: 62,96\% dos municípios atenderam razoavelmente a esse requisito, com destaque para a cidade do Rio de Janeiro. Assim, percebe-se a incorporação, pela gestão municipal, das determinações legais, como a Lei de Responsabilidade Fiscal, a Lei Federal 9.755/98 e a Lei Complementar $131 / 2009$.

Já com relação à qualidade na prestação de serviços via Internet, os municípios se apresentaram de maneira regular, destacando-se Belo Horizonte. No entanto, 100\% dos municípios analisados ainda apresentam algum tipo de carência quanto à realização de serviços através de seus portais, como, por exemplo, obtenção de formulários, preenchimento e oficialização de inscrições em concursos, cursos ou eventos, emissão de segunda via etc.

Em consonância com os dados apurados na pesquisa, pode-se afirmar que as capitais brasileiras ainda precisam melhorar a qualidade dos seus portais, para que possam realmente promover o acesso à informação de forma fácil, compreensível e rápida. As políticas direcionadas para o governo eletrônico carecem de melhor operacionalização para que se consolide uma democracia digital, em que os cidadãos tenham a alternativa de participação via Internet. A adoção dessas práticas permite o aumento da eficácia, da eficiência e da transparência governamental.

A partir dos resultados obtidos neste estudo, recomenda-se uma avaliação das demais práticas utilizadas na gestão do conhecimento nas capitais brasileiras, com o intuito de diagnosticar mais exatamente em que aspectos e atributos os governos precisam aperfeiçoar 
suas tecnologias de informação, como: capacitação de pessoal, infraestrutura tecnológica, planejamento para desenvolver a gestão do conhecimento etc. Também se recomenda uma comparação com os estudos já realizados para construir um perfil do desenvolvimento da gestão da informação no país.

\section{Referências}

ALVARENGA NETO, R.C.D. Gestão do conhecimento em organizações: proposta de mapeamento conceitual integrativo. 2005. Tese (Doutorado em Ciência da Informação) - Universidade Federal de Minas Gerais, Belo Horizonte, 2005.

ANDRADE, N.A. Contabilidade pública na gestão municipal. 3. ed. São Paulo: Atlas, 2007.

BATISTA, F.F. O governo que aprende: implementando a gestão do conhecimento no Executivo Federal, gestão estratégica da informação e inteligência competitiva. São Paulo: Saraiva, 2006. p.185-194.

BATISTA, F.F. et al. Gestão do conhecimento na administração pública. Brasília, 2005. Disponível em: <http://www.terra forum.com.br/biblioteca/Documents/libdoc00000229v001 relatorio_ipea.pdf>. Acesso em: 10 jun. 2010.

BRASIL. [Constituição (1988)]. Constituição Federal 1988. 19.ed. Brasília: Cedi, 2002.

BRASIL. Ministério do Planejamento, Orçamento e Gestão. Indicadores e métricas para avaliação de e-serviços. Brasília: MP, 2007.

BIZ, A.A. Avaliação dos portais turísticos governamentais quanto ao suporte à gestão do conhecimento. 2009. Tese (Doutorado em Engenharia e Gestão do Conhecimento) - Universidade Federal de Santa Catarina, Florianópolis, 2009.

COELHO, E.M. Gestão do conhecimento como sistema de gestão para o setor público. Revista do Serviço Público, v.55, n.1-2, 2004. Disponível em: <http://www.dominiopublico. gov.br/pesquisa/DetalheObraForm.do?select_action $=\&$ co_obra $=6>$. Acesso em: 22 maio 2010 .

COSTA, M.D.; KRUCKEN, L.; ABREU, A.F. Gestão da informação ou gestão do conhecimento? Florianópolis, 2010. Disponível em: <http://revista.acbsc.org.br>. Acesso em: 20 jun. 2010.

DAVENPORT, T.; PRUSAK, L. Conhecimento empresarial. Rio de Janeiro: Campus, 1998.

DROPA, R.F. Reforma do estado e reforma administrativa. 2003. Disponível em: <http://www.advogado.adv.br/artigos/2003/ romualdoflaviodropa/reformaestado.htm>. Acesso em: 25 maio 2010.

DRUCKER, P.A. Sociedades pós-capitalista. Rio de Janeiro: Pioneira, 1993.

DRUCKER, P.F. As novas realidades. 4. ed. São Paulo: Pioneira, 1997.

FERNANDES, A.G.; AFONSO, J.R.R. e-Governo no Brasil: experiências e perspectivas. Revista do BNDES, v.8, n.5, p.21-64, 2001.
FRESNEDA, P.S.V:; GONÇALVES, S.M.G. A Experiência brasileira na formulação de uma proposta de política de gestão do conhecimento para a administração pública federal. Brasília: Câmara dos Deputados, 2007.

GIL, A.C. Como elaborar projetos de pesquisa. 3.ed. São Paulo: Atlas, 1996.

JARDIM, J.M. Capacidade governativa, informação e governo eletrônico. DataGramaZero, v.1, n.5, 2000. Disponível em: <http://www.dg3.org.br/out06/Art_02.html>.

LENK, K.; TRAUNMULLER, R. Broadening the concept of electronic government. In: PRINS, J.E.J. (Ed.). Designing e-government. [S. I.]: Kluwer Law International, 2001. p.63-74.

MARINI, C. Gestão pública: o debate contemporâneo. Salvador: FLEM, 2003. 104p. (Cadernos FLEM, 7, versão completa).

MATIAS, A.B.; CAMPELLO, C.A.G.B. Administração financeira municipal. São Paulo: Atlas, 2000

MATOS, R.A. Para que modernizar a organização pública? Revista de Administração Pública, v.22, n.3, p.22-26, 1988.

MODRO, N.R. Gestão do conhecimento \& governo eletrônico: uma visão sistêmica para os observatórios sobre drogas. 2005. Tese (Doutorado em Engenharia de Produção e Sistemas) - Universidade Federal de Santa Catarina, Florianópolis, 2005.

NONAKA, I. A dynamic theory of organizational knowledge creation. Organization Science, v.5, n.1, p.14-37, 1994.

PARREIRAS, T.A.S.; CARDOSO, A.M.; PARREIRAS, F.S. Governo eletrônico: uma avaliação do site da Assembléia Legislativa de Minas Gerais. In: CINFORM, 5., 2004, Salvador. Anais... Salvador: UFBA, 2004. Disponível em: <http://www.fernando.parreiras. nom.br/publicacoes/egov_cinform.pdf $>$. Acesso em: 5 maio 2010.

PAULA, D.R.; CIANCONE, R.B. Práticas de gestão do conhecimento: caso dos sítios associados ao portal corporativo da Fiocruz. Perspectivas em Ciência da Informação, v.12, n.2, p.49-63, 2007.

PEREIRA, A.D.S.; RIBEIRO, C.P.P.; BARBOSA, T.M. A Gestão do conhecimento como um instrumento para auxiliar os poderes executivos e legislativos na promoção de uma comunicação eficiente entre o governo e o cidadão. In: CONGRESSO NACIONAL DE GESTÃO DO CONHECIMENTO, 9., 2010, Gramado. Anais... Gramado, 2010.

REIS, C. Planeamento estratégico de sistemas de informação. Lisboa: Presença, 1993. p.20-24.

RIBEIRO, C.P.P.; ZUCCOLOTTO, R. Índice de transparência fiscal das contas públicas dos municípios obtidos em meios eletrônicos 
de acesso público. 2008. Disponível em: <http://www.anpad. org.br>. Acesso em: 20 abr. 2010.

SALLES, C.A.C Gestão do conhecimento versus administração pública. Rio de Janeiro, 2009. Disponível em: <http://www. artigos.com>. Acesso em: 19 jun. 2010.

SIMÃO, J.B.; RODRIGUES, G. Acessibilidade às informações públicas: uma avalição do portal de serviços e informações do governo federal. Ciência da Informação, v.34, n.2, p.81-92, 2005. Disponível em: <http://www.ibict.br/cienciada informacao>. Acesso em: 14 set. 2010.

SILVA, T.E.; TOMAÉL, M.I. Editorial: a gestão da informação nas organizações. Informação \& Informação, v.12, n.2, p.0-0, 2007.

SOCIEDADE da informação no Brasil: livro verde. Brasília: MCT, 2000.

SOUZA, W. Tecnologia da informação e transparência governamental. 2005. Dissertação (Mestrado em Educação, Administração e Comunicação) - Universidade Federal de São Marcos, São Paulo, 2005.
TEIXEIRA FILHO, J. Gerenciando conhecimento: como a empresa pode usar a memória organizacional e a inteligência competitiva no desenvolvimento de negócios. Rio de Janeiro: SENAC, 2000 .

TERRA, J.C.; GORDON, C. Portais corporativos: a revolução na gestão do conhecimento. São Paulo: Negócio, 2002.

VAZ, J.C. Limites e possibilidades do uso de portais municipais para promoção da cidadania: a construção de um modelo de análise e avaliação. 2003. Tese (Doutorado) - Fundação Getúlio Vargas, São Paulo, 2003.

VAZ, J.C. Referencial teórico-conceitual para análise e avaliação de portais municipais para o atendimento ao cidadão. In: ENCONTRO DE ADMINISTRAÇÃO DA INFORMAÇÃO DA ANPAD, 1., 2007, Florianópolis. Anais... Florianópolis: 2007.

VILLELA, R.M. Conteúdo, usabilidade e funcionalidade: três dimensões para avaliação de portais estaduais de governo eletrônico na web. 2003. Dissertação (Mestrado em Ciência da Informação) - Universidade Federal de Minas Gerais, Belo Horizonte, 2003. 